\title{
Maturation of NMDA receptor-mediated spontaneous postsynaptic currents in the rat locus coeruleus neurons
}

\author{
M KOUROSH-ARAMI ${ }^{1,2 *}$ (1) and S HAJIZADEH ${ }^{1}$ \\ ${ }^{1}$ Department of Physiology, Faculty of Medical Sciences, Tarbiat Modares University, Tehran, Iran \\ ${ }^{2}$ Department of Neuroscience, School of Advanced Technologies in Medicine, Iran University of \\ Medical Sciences, Tehran, Iran
}

Received: August 4, 2019 • Accepted: January 28, 2020

Published online: April 23, 2020

(C) 2020 Akadémiai Kiadó, Budapest

\begin{abstract}
Introduction: During mammalian brain development, neural activity leads to maturation of glutamatergic innervations to locus coeruleus. In this study, fast excitatory postsynaptic currents mediated by N-methyl-Daspartate (NMDA) receptors were evaluated to investigate the maturation of excitatory postsynaptic currents in locus coeruleus (LC) neurons. Methods: NMDA receptor-mediated synaptic currents in LC neurons were evaluated using whole-cell voltage-clamp recording during the primary postnatal weeks. This technique was used to calculate the optimum holding potential for NMDA receptor-mediated currents and the best frequency for detecting spontaneous excitatory postsynaptic currents (sEPSC). Results: The optimum holding potential for detecting NMDA receptor-mediated currents was +40 to $+50 \mathrm{mV}$ in LC neurons. The frequency, amplitude, rise time, and decay time constant of synaptic responses depended on the age of the animal and increased during postnatal maturation. Conclusion: These findings suggest that most nascent glutamatergic synapses express functional NMDA receptors in the postnatal coerulear neurons, and that the activities of the neurons in this region demonstrate an age-dependent variation.
\end{abstract}

\section{KEYWORDS}

locus coeruleus, NMDA receptor, spontaneous activity, postnatal development, excitatory postsynaptic currents, patch clamp

\footnotetext{
* Corresponding author. Department of Neuroscience, School of Advanced Technologies in Medicine, Iran University of Medical Sciences, Tehran, Iran, E-mail: kourosharami.m@iums.ac.ir
} 


\section{INTRODUCTION}

In the early phases of brain development, some brain synapses only include N-methyl-daspartate (NMDA) receptors, AMPA receptors are added at a later stage [41]. In the visual cortical synapses, NMDA components of EPSCs are modulated by neural activity in order to maintain a constant ratio between AMPA and NMDA EPSCs [12, 41]. Previous studies have shown significant alterations in glutamatergic neurotransmission from birth to maturity. A striking finding is the modification of the ratio of NMDA EPSC amplitude to AMPA EPSC amplitude, which reaches its peak at the second postnatal week, after which it starts to fall until maturity [45]. It has been reported that NMDA receptor activation is voltage-dependent, and therefore any changes in their percentage can impact paired-pulse plasticity [22].

Widespread noradrenergic projections reach extensive areas of the central nervous system from the pontine locus coeruleus (LC) and have a modulatory effect in cognitive performance, alertness, learning and memory $[16,17,27,42]$. The excitability of LC neurons is controlled by excitatory synaptic inputs that mostly derives from the nucleus paragigantocellularis (PGi) [46], and in vivo administration of glutamate receptor agonists can enhance the firing rate of LC neurons [20]. Therefore, for LC to apply its modulatory role, its glutamatergic innervations must be accurately adjusted during postnatal brain development $[4,39]$.

In glutamatergic synapses, NMDA receptors cause slow excitation and create a much slower and longer-lasting current of $\mathrm{Ca}^{2+}$ ions. Hence, NMDA receptor levels at a particular synapse have a significant effect on the time course and summation of synaptic currents [25, 31]. Based on this, in this paper we have characterized the maturation of NMDA-dependent synaptic properties of LC neurons to reveal the role of NMDA receptors in LC functions during brain development.

\section{EXPERIMENTAL PROCEDURE}

\section{Animals}

Eighteen male albino Wistar rats (P7-21), purchased from Pasteur Institute, Tehran, Iran, were kept at $25 \pm 2{ }^{\circ} \mathrm{C}$ in a humidity-controlled room with a 12:12 h light/dark cycle; lights were turned on at 7:00 a.m. and rodents were given free access to food and water, except during behavioral tests, which were performed during the light phase. The ethical guidelines of the "Ethical Committee of Faculty of Medical Sciences, Iran University", which is based on the "NIH Guide for the Care and Use of Laboratory Animals", were followed in all the experiments.

\section{Electrophysiological experiments}

Male Wistar rats were anesthetized on P7, or P14, or P21 using ether inhalation and decapitated. The brain was rapidly removed $(<1 \mathrm{~min})$ along with the brainstem and placed instantaneously into an ice-cold (about $1{ }^{\circ} \mathrm{C}$ ) Petri dish, where it was oxygenated $\left(95 \% \mathrm{O}_{2}-5 \% \mathrm{CO}_{2}\right)$ for approximately $1 \mathrm{~min}$ using cutting solution with the following composition (in $\mathrm{mM}$ ): 248 sucrose, $28 \mathrm{NaHCO}_{3}, 10$ glucose, $5 \mathrm{KCl}, 1.26 \mathrm{NaH}_{2} \mathrm{PO}_{4}-\mathrm{H}_{2} \mathrm{O}$ and $1.3 \mathrm{MgSO}_{4}-7 \mathrm{H}_{2} \mathrm{O},[3,38] .400$ $\mu \mathrm{m}$ coronal slices were prepared from the brainstem using a vibratome slicer. Coronal slices, including the LC, were sectioned from each hemisphere and equilibrated at room temperature 
for a minimum $1 \mathrm{~h}$ in ACSF with the following composition (mM): $\mathrm{NaCl} 126, \mathrm{MgSO}_{4} 2, \mathrm{KCl}$, $\mathrm{NaHCO}_{3} 25, \mathrm{NaH}_{2} \mathrm{PO}_{4} 1$, dextrose 10 and $\mathrm{CaCl}_{2}$ 2. The slices were bubbled with a mixture of $95 \% \mathrm{O}_{2}$ and $5 \% \mathrm{CO}_{2}$ before recording $[7,31]$. Slices were separately transported to a recording chamber where they received circulating and bubbled ACSF at $30-32{ }^{\circ} \mathrm{C}$. The anatomic sites of recordings were evaluated with reference to 'The Rat Brain in Stereotaxic Coordinates' by Paxinos and Watson, using the position of the 4th ventricle as the major landmark. The anterior/posterior positions of LC slices were observed in plates [9-11] of the Atlas [34]. Glass micropipettes (thin-walled capillary tubing, Warner Instruments) were pulled on a FlamingBrown horizontal puller (Sutter). A potassium-gluconate-based internal solution was applied for measuring postsynaptic membrane currents, consisting of $(\mathrm{mM})$ : potassium gluconate $95, \mathrm{NaCl}$ 15, $\mathrm{KCl} 30$, Hepes 10, $\mathrm{MgCl}_{2}$ 1, MgATP 2, EGTA 11, NaGTP 0.25 and pH 7.3. Osmolarity was 280-290 mOsm. LC neurons were illuminated and visualized using infrared Nomarski optics and a water-immersion objective lens (X40) mounted on a microscope. A charge-coupled device camera transmitted the image to a monitor screen. Whole-cell current-clamp recordings were accomplished $\leq 6 \mathrm{~h}$ following slicing using a MultiClamp 700B amplifier (Axon Instruments) and pClamp 10 software (Molecular Devices, USA), with a $3 \mathrm{kHz}$ low-pass Bessel filter, and digitized at $10 \mathrm{kHz}$ using a Digidata 1440A data acquisition system (Molecular Devices, USA).

The series resistance was checked periodically throughout the experiment and $<30 \mathrm{M} \Omega$ was considered acceptable $[26,31]$. The recording was terminated if the access resistance changed more than $15 \%$.

To isolate excitatory sEPSCs and omit the activity of the inhibitory synapses, bicuculline (50 $\mu \mathrm{M}$ ) was added to the ACSF circulating in the recording chamber. The amplitude and frequency of each sEPSC in glutamatergic synapses of LC was measured during the first three weeks of postnatal period. Slices were transported from $2 \mathrm{mM} \mathrm{Mg}^{2+}$ ACSF to an $\mathrm{Mg}^{2+}$-free recording chamber for $\geq 25 \mathrm{~min}$ in order to wash away $\mathrm{Mg}^{2+}$ from the slices [31]. NMDA sEPSCs were recorded at $+40 \mathrm{mV}$.

Initially, EPSC was recorded while holding the cell potential at $+40 \mathrm{mV}$ to provide sufficient depolarization to reveal the NMDA EPSC. Once 25-50 responses were recorded, 6 cyano-7nitroquinoxaline-2, 3-dione (CNQX; $50 \mu \mathrm{M}$ ) was added to the ACSF circulating in the recording chamber in order to trigger NMDAR-mediated EPSCs. From each cell, 10-20 trials were averaged for analysis. In addition, the peak NMDAR-mediated EPSC can be measured by subtracting the EPSC recorded in the presence of APV from the baseline EPSC [7, 14].

\section{Drugs and statistical analysis}

The chemical compounds used in current study were as follows: bicuculline (Sigma Aldrich, USA) and CNQX (Tocris, USA). Data were expressed as mean \pm SEM. Statistical significance between means for electrophysiological data was analyzed using One Way ANOVA and Tukey's post-hoc test. $P<0.05$ was used as the confidence level for all statistical tests.

\section{RESULTS}

Membrane potentials of LC neurons were recorded under current-clamp technique using wholecell patch-clamp methods in developing rats. The mean resting membrane potential (RMP) was 
$-53.97 \pm 1.86 \mathrm{mV}(\mathrm{n}=10)$. The input resistance of the LC neurons was $258.5 \pm 12.3 \mathrm{M} \Omega$ $(\mathrm{n}=11)$ and capacitance was $123.5 \pm 11.13$.

Our aim was to record the activity of NMDA EPSCs in LC neurons. Slices were transferred to an $\mathrm{Mg}^{2+}$-free recording chamber for $\geq 25 \mathrm{~min}$ to wash this ion from the slices and thus remove the blocking effect of $\mathrm{Mg}^{2+}$ on NMDA receptors [31]. In order to find the optimal recording potential for measuring NMDA EPSCs, we produced an amplitude-voltage (I-V) relation chart using different potentials in the presence of $50 \mu \mathrm{M}$ CNQX in nominally zero extracellular $\mathrm{Mg}^{2+}$ (Fig. 1), which showed that maximal NMDA EPSC amplitude was at +40 to $+50 \mathrm{mV}$. Baseline EPSCs are dual-component, containing both NMDA and AMPA EPSCs. Initially, EPSC was recorded while holding the cell potential at +40 to $+50 \mathrm{mV}$ (as previously explained) to provide sufficient depolarization to reveal the NMDAR EPSC. For complete isolation of the NMDA receptor-mediated component of the EPSCs (NMDA EPSC), we added CNQX $(50 \mu \mathrm{M})$, known as an AMPA receptor antagonist, to block non-NMDA receptors and produce pure NMDAR-mediated EPSCs. In addition, to verify that this EPSC recording was due
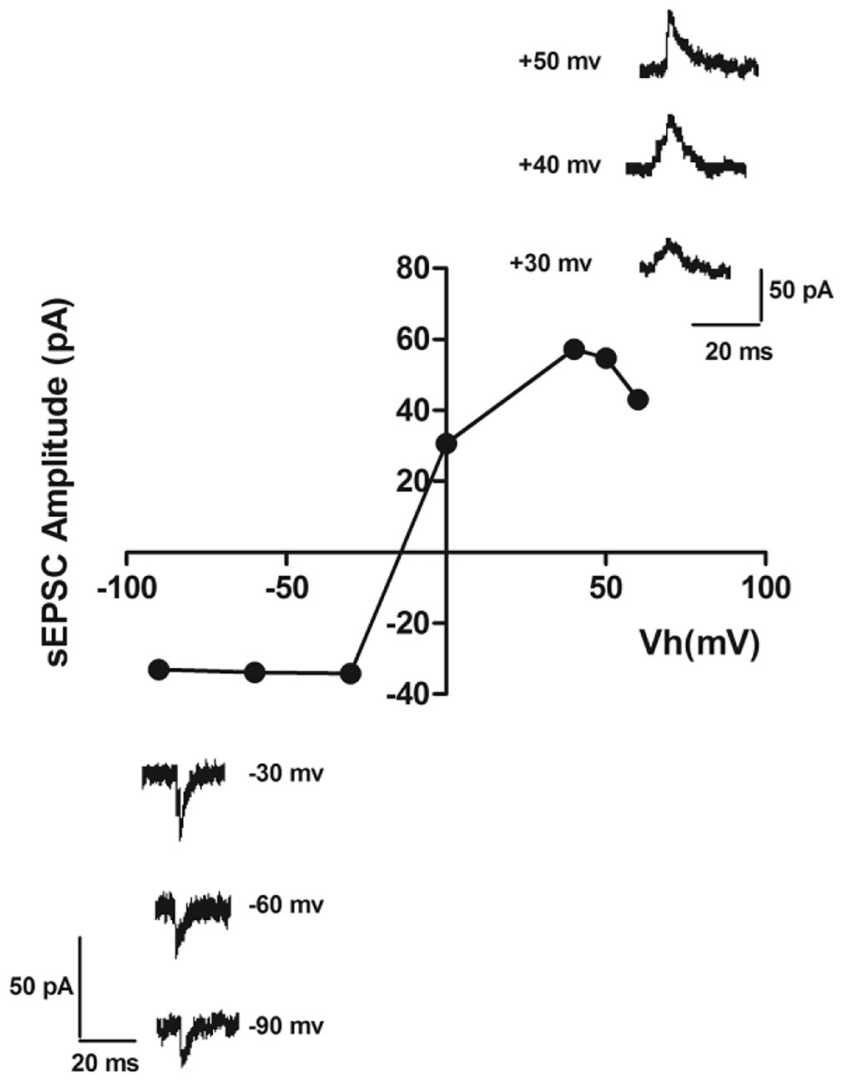

Fig. 1. Current-voltage relationships for NMDA sEPSCs of coerulear neurons. Sample sweeps exemplifying NMDA sEPSCs recorded at different holding potentials. The graph shows I-V relationship for NMDA sEPSCs 

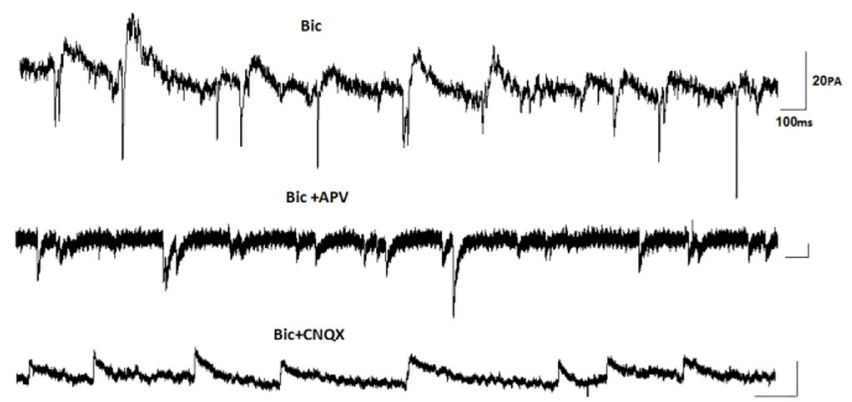

$B i C+A P V+C N Q X$

Fig. 2. Sample sweeps illustrating recorded EPSPs in locus coeruleus neurons produced in the presence of bicuculine (top trace), Bic + APV (second trace), Bic + CNQX (third trace) and Bic + APV+ CNQX (bottom trace)
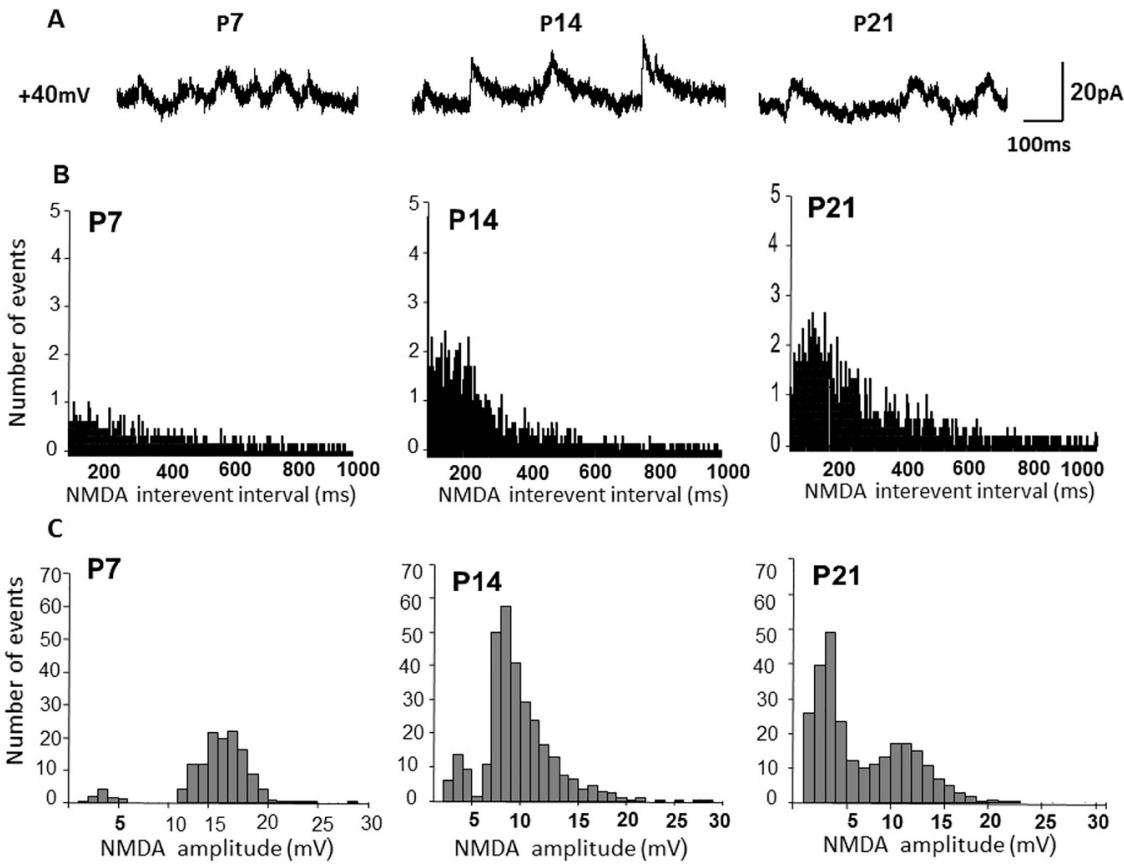

Fig. 3. Alteration of NMDA receptor sEPSCs in postnatal locus coeruleus neurons among the three age groups. A. Sample sweeps illustrating NMDA sEPSCs recorded at $+40 \mathrm{mV}$ (top trace) at different postnatal ages. B. Histogram of interevent intervals for NMDA sEPSCs. C. Amplitude histograms of NMDA sEPSCs in P7, P14 and P21 
to NMDA receptors, we can add amino-5-phosphonovaleric acid (APV; $50 \mu \mathrm{M}$ ), a selective NMDA receptor antagonist, that blocks NMDA EPSCs (Fig. 2). As another alternative way for measuring NMDA EPSC in some neurons, we can subtract the EPSCs recorded in the presence of APV from the baseline EPSC [1,2]. EPSCs were depressed after applying APV (20-30\% reduction in the amplitude) and almost completely blocked by the simultaneous application of CNQX and APV (Fig. 2).

Figure 3 demonstrates recordings of NMDA sEPSCs at $+40 \mathrm{mV}$ during brain development. Representative traces of NMDAR-mediated sEPSCs at different ages are shown in Fig. 3A. The interevent interval histograms of NMDA sEPSCs in different postnatal ages are shown in Fig. 3B. Fig. 3C displays amplitude histograms of NMDA sEPSCs during postnatal maturation. EPSP amplitudes ranged from 5-20 mV and there was a significant increase in EPSP amplitude between P7-P21. EPSC amplitude was evaluated by baselining each EPSC over a $2 \mathrm{~ms}$ window immediately before the peak and then averaging it over a $1 \mathrm{~ms}$ window around the peak [6].

NMDA receptor kinetics change during brain development in the first postnatal weeks. Fig. 4 shows sample sweeps demonstrating NMDA sEPSCs recorded at $+40 \mathrm{mV}$ at different postnatal weeks (Fig. 4A). Fig. 4 shows the rise and decay time-constant of NMDA EPSCs. Comparisons

A

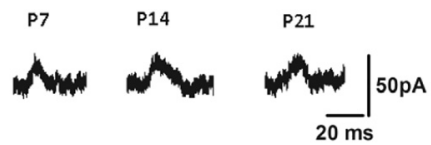

B

C
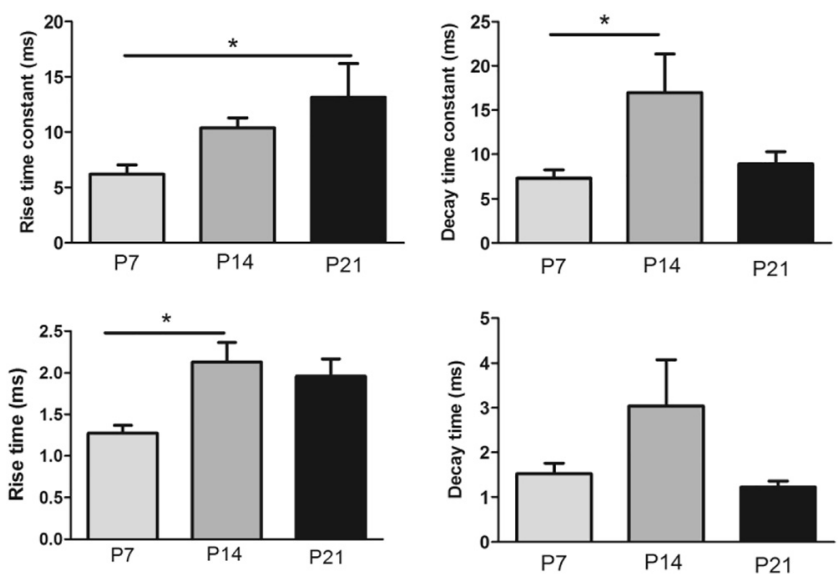

Fig. 4. Developmental changes in kinetics of spontaneous EPSC. A. Sample sweeps demonstrating NMDA sEPSCs recorded at $+40 \mathrm{mV}$ at different postnatal weeks. B. Rising time constant of NMDA sEPSC demonstrated a significant change in P21 with respect to P7. Rising time of NMDA sEPSC showed a significant change in P14 with respect to P7; C. the graphs of the decay time constant and decay time of NMDA sEPSC. Decay time constant demonstrated a significant difference in 2nd week of age with respect to the earliest age. All data are expressed as means \pm SEM $(* P<0.05 ; \mathrm{n}=8)$ 
of the rising time-constant demonstrated a significant change in P21 with respect to P7 in all recorded neurons $(P \leq 0.05$; Fig. $4 \mathrm{~B})$. Rise time increased in $\mathrm{P} 14$ in approximately $75 \%$ of the recorded neurons) $(P \leq 0.01)$ compared to P7. The decay time-constant of NMDAR EPSCs in coerulear cells revealed a significant increase on the second week after birth compared to the first week in $80 \%$ of the recorded neurons ( $P \leq 0.05$; Fig. $4 \mathrm{C})$. No changes resulting from development were observed in decay time values.

Rise time was described as the interval between the beginning of the rising phase and the peak (rise time), and decay time was defined as the interval between the peak and $90 \%$ of the decaying phase (decay time) [35]. Time for spike to rise from threshold to peak is usually calculated as the time needed for the potential to increase from $10 \%$ of its peak to $90 \%$. Timeconstant is the time needed for a membrane to repolarize after a small current is injected with a fixed amplitude and duration. The higher the time-constant, the slower the increase or decrease of the potential of a neuron. All these items were measured by Clampfit software.

\section{DISCUSSION}

In the present patch-clamp study, we used LC slices. Many of the afferent axons of the LC were severed during the preparation of the slices. Moreover, the spontaneous activity of one neuron could emerge from many inputs $[1,43]$, which is why we chose to record and study spontaneous activity.

Recording the NMDA-dependent currents required finding the optimal potential for sEPSC detection. This was accomplished using several methods, including estimation of the currentvoltage $(\mathrm{I}-\mathrm{V})$ curve. Therefore, we first recorded sEPSCs of LC neurons at different holding potentials to acquire the I-V curve. The curve revealed that the optimal holding potential for detecting NMDA sEPSCs is +40 to $+50 \mathrm{mv}$. According to our results, an augmented membrane polarization (EPSC driving force) beyond +40 to $+50 \mathrm{mV}$ does not increase amplitude detection and saturates at these values. Therefore, these values of holding potentials are optimal for NMDA sEPSCs detection in LC neurons. It is evident that at membrane voltages close to resting potential (between-90 and $-40 \mathrm{mV}$ ), only a small fraction of the peak current flows through NMDA receptor channels. The extracellular $\mathrm{Mg}^{2+}$ blocks NMDA receptors at negative levels of membrane voltages [28, 32]. Therefore, our results show that the contribution of NMDA to EPSCs reaching their peak steadily increases with depolarization and becomes dominant at positive voltages. Furthermore, analysis of sEPSCs produces relatively unbiased recording from the abundant synapses that terminate on a single cell. However, because of the noise at baseline recordings in nominally zero $\mathrm{Mg}^{2+}$, the signal-to-noise ratio was so low that we had to use the optimal potential for inducing the largest sEPSCs instead.

In the next step, we recorded NMDA sEPSCs during brain development. As the results demonstrate, the amplitude and frequency of NMDA sEPSCs increased during the primary postnatal weeks. The frequency enhancement shows an augmentation in the dendritic tree, in addition to the number of synapses per cell in this period [2, 24]. Furthermore, the comparable increase in the amplitude of NMDA sEPSCs can be explained as an enhancement in the number of NMDA receptors, which, in fact, may show an enhancement in the average size of the synapses [1]. Variation in NMDA-receptor-mediated EPSCs during brain development has been 
examined in many previous studies [8]. Nonetheless, some of them have demonstrated no developmental variation in the amplitude of NMDA EPSCs.

\section{MATURATION OF THE KINETIC PROPERTIES OF NMDA sEPSCs}

To complete our quantitative analysis of sEPSCs recording, we measured the kinetics of NMDAR sEPSCs. Analysis of the rise times of NMDA EPSCs in LC neurons in nominally zero $\mathrm{Mg}^{2+}$ revealed significant differences between them. Most notable was the finding of very slowly rising NMDA sEPSCs in the majority of LC neurons. Another characteristic of the NMDA sEPSCs in coerulear cells in the present study was the slow decay times. Furthermore, by virtue of NMDA voltage sensitivity, this kind of glutamatergic receptors causes an enormous increase in synaptic charge transfer, and consequently, $\mathrm{Ca}^{2+}$ entry upon depolarization [18].

Developmental changes in NMDA sEPSC kinetics have been detected in numerous areas of the CNS [5]. In CA1 neurons, NMDA EPSC duration displayed the developmental decrease that originates from the decrement of glutamate binding affinity to synaptic NMDA receptors in adult rats compared to young ones [19]. In dentate gyrus granule cells, NMDA sEPSCs demonstrated a maturational reduction in rise time, but no change in decay time [44]. In the fast spiking cells of rat prefrontal cortex, changes in membrane time-constants of NMDAR-EPSC appeared to be age-independent, but the decay times were age-dependent [40].

In our study, synaptic decay time constants in P14 were higher than that in P7; however, sEPSC decay time did not change during the primary postnatal weeks in LC neurons. Shorter synaptic decay constants in P7 with respect to P14 might augment temporal fidelity and the ability to follow repetitive low-frequency presynaptic stimuli. The expression profile of the different subunits throughout the brain changes with brain development [29], suggesting a possible causal relation between alterations in subunit composition and in functional properties of these receptors [30]. It is possible that the transition from NR2B (slow kinetics) to NR2A (faster kinetics) subunits in NMDA receptors during brain development $[9,15,33]$ contributes to a decline in synaptic decay constants with age. At most glutamatergic synapses, the NR2B subunits of NMDA receptors are gradually replaced by NR2A subunits during brain development [10]. Another explanation for sEPSCs decay time changes arises from a different rate of transmitter clearance by glutamate transporters [21]. In the nucleus tractus solitaries, which is the site of the first synapse of baroreceptor fibers [23], glutamate binding to NMDA receptors was augmented by about 50-70\% between birth and postnatal day 9 and then reduced until P30 [36]. The nucleus raphe magnus as a thermoregulation center [47] affects on cortical hyperexcitability and facilitates trigeminal nociception in a rat model of medication overuse. Glutamate binding enhancement increases the decay time of EPSCs [1].

As the results show, the synaptic rising constants in P21 were higher than that in P7 and P14, and sEPSC rise time in P14 was higher than that in P7 during postnatal ages in LC neurons. The duration of the rise time was influenced by the location of the synaptic stimulation, suggesting that the observed variability in this factor in our results reveals the filter properties of the dendritic resistance and capacitance. For synaptic currents produced at proximal synaptic locations, rise time is faster, whereas more distal synaptic locations are indicated by slower rise times [5]. In conclusion, the current developmental changes in rise time show that after birth, proximal synaptic contacts are constructed first in a LC neuron and the more distal synaptic 
locations are constructed later during brain development. Accordingly, NMDA EPSCs would be more effective in transmitting the electrical signals in young, rather than adult, LC neurons.

Together with the previous findings $[11,13,37]$, the present results demonstrate that the vast majority of corulear glutamatergic synapses are born "mature", in other words, they express functional NMDA receptors. Our results provide insight into the development of NMDA-dependent sEPSC of LC neurons. Additional studies are needed to identify the particular role of these agerelated changes in the synaptic properties of LC neurons throughout the lifetime of animals.

Conflict of interest: The authors declare no conflict of interest.

\section{ACKNOWLEDGMENTS}

The authors would like to thank Tarbiat Modares University for their financial support. We also thank INSF for supporting this study.

\section{REFERENCES}

1. Arami MK, Hajizadeh S, Semnanian S. Postnatal development changes in excitatory synaptic activity in the rat locus coeruleus neurons. Brain Res 2016; 1648: 365-71, https://doi.org/10.1016/j.brainres.2016.07.036.

2. Arami MK, Semnanian S, Javan M, Hajizadeh S, Sarihi A. Postnatal developmental alterations in the locus coeruleus neuronal fast excitatory postsynaptic currents mediated by ionotropic glutamate receptors of rat. Physiol Pharmacolog 2011; 14: 337-48.

3. Arami MK, Sohya K, Sarihi A, Jiang B, Yanagawa Y, Tsumoto T. Reciprocal homosynaptic and heterosynaptic long-term plasticity of corticogeniculate projection neurons in layer VI of the mouse visual cortex. J Neurosci 2013; 33: 7787-98, https://doi.org/10.1523/JNEUROSCI.5350-12.2013.

4. Aston-Jones G, Shipley M, Chouvet G, Ennis M, Van Bockstaele E, Pieribone V, et al. Afferent regulation of locus coeruleus neurons: anatomy, physiology and pharmacology. Prog Brain Res 1991; 88: 47-75, https://doi. org/10.1016/S0079-6123(08)63799-1.

5. Bardoni R, Magherini PC, MacDermott AB. NMDA EPSCs at glutamatergic synapses in the spinal cord dorsal horn of the postnatal rat. J Neurosci 1998; 18: 6558-67, https://doi.org/10.1523/JNEUROSCI.18-1606558.1998 .

6. Bekkers JM, Clements JD. Quantal amplitude and quantal variance of strontium-induced asynchronous EPSCs in rat dentate granule neurons. J Physiol 1999; 516: 227-48, https://doi.org/10.1111/j.1469-7793.1999. 227aa.x.

7. Bottjer SW. Silent synapses in a thalamo-cortical circuit necessary for song learning in zebra finches. J Neurophysiol 2005; 94: 3698-707, https://doi.org/10.1152/jn.00282.2005.

8. Burgard EC, Hablitz JJ. NMDA receptor-mediated components of miniature excitatory synaptic currents in developing rat neocortex. J Neurophysiol 1993; 70: 1841-52, https://doi.org/10.1152/jn.1993.70.5.1841.

9. Cull-Candy S, Brickley S, Farrant M. NMDA receptor subunits: diversity, development and disease. Curr Opin Neurobiol 2001; 11: 327-35, https://doi.org/10.1016/S0959-4388(00)00215-4. 
10. de Armentia ML, Sah P. Development and subunit composition of synaptic NMDA receptors in the amygdala: NR2B synapses in the adult central amygdala. J Neurosci 2003; 23: 6876-83, https://doi.org/10. 1523/JNEUROSCI.23-17-06876.2003.

11. Friedman D, Strowbridge BW. Functional role of NMDA autoreceptors in olfactory mitral cells. J Neurophysiol 2000; 84: 39-50, https://doi.org/10.1152/jn.2000.84.1.39.

12. Friedman HV, Bresler T, Garner CC, Ziv NE. Assembly of new individual excitatory synapses: time course and temporal order of synaptic molecule recruitment. Neuron 2000; 27: 57-69, https://doi.org/10.1016/S08966273(00)00009-X.

13. Gasparini S, Saviane C, Voronin LL, Cherubini E. Silent synapses in the developing hippocampus: lack of functional AMPA receptors or low probability of glutamate release? Proc Natl Acad Sci U S A 2000; 97: 9741-46, https://doi.org/10.1073/pnas.170032297.

14. Hsia AY, Malenka RC, Nicoll RA. Development of excitatory circuitry in the hippocampus. J Neurophysiol 1998; 79: 2013-24, https://doi.org/10.1152/jn.1998.79.4.2013.

15. Hsieh CY, Chen Y, Leslie FM, Metherate R. Postnatal development of NR2A and NR2B mRNA expression in rat auditory cortex and thalamus. J Assoc Res Otolaryngol 2002; 3: 479-87, https://doi.org/10.1007/ s1016200220528.

16. Ishibashi H, Nakahata Y, Eto K, Nabekura J. Excitation of locus coeruleus noradrenergic neurons by thyrotropin-releasing hormone. J Physiol 2009; 587: 5709-22, https://doi.org/10.1113/jphysiol.2009.181420.

17. Ishimatsu M, Williams JT. Synchronous activity in locus coeruleus results from dendritic interactions in pericoerulear regions. J Neurosci 1996; 16: 5196-204, https://doi.org/10.1523/JNEUROSCI.16-16-05196.1996.

18. Keller B, Konnerth A, Yaari Y. Patch clamp analysis of excitatory synaptic currents in granule cells of rat hippocampus. J Physiol 1991; 435: 275-93, https://doi.org/10.1113/jphysiol.1991.sp018510.

19. Kirson ED, Yaari Y. Synaptic NMDA receptors in developing mouse hippocampal neurones: functional properties and sensitivity to ifenprodil. J Physiol 1996; 497: 437-55, https://doi.org/10.1113/jphysiol.1996. sp021779.

20. Koga H, Ishibashi H, Shimada H, Jang I-S, Nakamura TY, Nabekura J. Activation of presynaptic GABA A receptors increases spontaneous glutamate release onto noradrenergic neurons of the rat locus coeruleus. Brain Res 2005; 1046: 24-31, https://doi.org/10.1016/j.brainres.2005.03.026.

21. Koike-Tani M, Saitoh N, Takahashi T. Mechanisms underlying developmental speeding in AMPA-EPSC decay time at the calyx of Held. J Neurosci 2005; 25: 199-207, https://doi.org/10.1523/JNEUROSCI.3861-04. 2005.

22. Komaki A, Shahidi S, Sarihi A, Hasanein P, Lashgari R, Haghparast A, et al. Effects of neonatal C-fiber depletion on interaction between neocortical short-term and long-term plasticity. Basic Clin Neurosci 2013; 4: 136-45.

23. Kourosh Arami M, Sarihi A, Malacoti SM, Behzadi G, Vahabian M, Amiri I. The effect of nucleus tractus solitarius nitric oxidergic neurons on blood pressure in diabetic rats. Iran Biomed J 2006; 10: 15-9.

24. López-Gallardo M, Prada C. Spatial and temporal patterns of morphogenesis of hippocampal pyramidal cells: study in the early postnatal rat. Hippocampus 2001; 11: 118-31, https://doi.org/10.1002/hipo.1030.

25. Malenka RC, Nicoll RA. Long-term potentiation-a decade of progress? Science 1999; 285: 1870-74, https:// doi.org/10.1126/science.285.5435.1870.

26. Marinelli S, Vaughan CW, Christie MJ, Connor M. Capsaicin activation of glutamatergic synaptic transmission in the rat locus coeruleus in vitro. J Physiol 2002; 543: 531-40, https://doi.org/10.1126/science.285. 5435.1870 .

27. Masaki E, Kawamura M, Kato F. Attenuation of gap-junction-mediated signaling facilitated anesthetic effect of sevoflurane in the central nervous system of rats. Anesth Analg 2004; 98: 647-52, https://doi.org/10.1213/ 01.ANE.0000103259.72635.72. 
28. Mayer ML, Westbrook GL, Guthrie PB. Voltage-dependent block by $\mathrm{Mg}_{2}{ }^{+}$of NMDA responses in spinal cord neurones. Nature 1984; 309: 261-63, https://doi.org/10.1038/309261a0.

29. Mori H, Mishina M. Structure and function of the NMDA receptor channel. Neuropharmacology 1995; 34: 1219-37, https://doi.org/10.1016/0028-3908(95)00109-J.

30. Moriyoshi K, Masu M, Ishii T, Shigemoto R, Mizuno N, Nakanishi S. Molecular cloning and characterization of the rat NMDA receptor. Nature 1991; 354: 31-7, https://doi.org/10.1038/354031a0.

31. Myme CI, Sugino K, Turrigiano GG, Nelson SB. The NMDA-to-AMPA ratio at synapses onto layer $2 / 3$ pyramidal neurons is conserved across prefrontal and visual cortices. J Neurophysiol 2003; 90: 771-79, https://doi.org/10.1152/jn.00070.2003.

32. Nowak L, Bregestovski P, Ascher P, Herbet A, Prochiantz A. Magnesium gates glutamate-activated channels in mouse central neurones. Nature 1984; 307: 462-65, https://doi.org/10.1038/307462a0.

33. Oswald A-MM, Reyes AD. Maturation of intrinsic and synaptic properties of layer $2 / 3$ pyramidal neurons in mouse auditory cortex. J Neurophysiol 2008; 99: 2998-3008, https://doi.org/10.1152/jn.01160.2007.

34. Paxinos G, Franklin KB. The mouse brain in stereotaxic coordinates. Oxford, UK: Gulf Professional Publishing; 2004.

35. Prè D, Nestor MW, Sproul AA, Jacob S, Koppensteiner P, Chinchalongporn V, et al. A time course analysis of the electrophysiological properties of neurons differentiated from human induced pluripotent stem cells (iPSCs). PLoS One 2014; 9: e103418, https://doi.org/10.1371/journal.pone.0103418.

36. Rao H, Jean A, Kessler J-P. Postnatal ontogeny of glutamate receptors in the rat nucleus tractus solitarii and ventrolateral medulla. J Auton Nerv Syst 1997; 65: 25-32, https://doi.org/10.1016/S0165-1838(97)00031-3.

37. Renger JJ, Egles C, Liu G. A developmental switch in neurotransmitter flux enhances synaptic efficacy by affecting AMPA receptor activation. Neuron 2001; 29: 469-84, https://doi.org/10.1016/S0896-6273(01) 00219-7.

38. Sarihi A, Mirnajafi-Zadeh J, Jiang B, Sohya K, Safari M-S, Arami MK, et al. Cell type-specific, presynaptic LTP of inhibitory synapses on fast-spiking GABAergic neurons in the mouse visual cortex. J Neurosci 2012; 32: 13189-99, https://doi.org/10.1523/JNEUROSCI.1386-12.2012.

39. Van Bockstaele EJ, Colago EE, Aicher S. Light and electron microscopic evidence for topographic and monosynaptic projections from neurons in the ventral medulla to noradrenergic dendrites in the rat locus coeruleus. Brain Res 1998; 784: 123-38, https://doi.org/10.1016/S0006-8993(97)01250-X.

40. Wang H-X, Gao W-J. Cell type-specific development of NMDA receptors in the interneurons of rat prefrontal cortex. Neuropsychopharmacology 2009; 34: 2028-40, https://doi.org/10.1038/npp.2009.20.

41. Watt AJ, van Rossum MC, MacLeod KM, Nelson SB, Turrigiano GG. Activity coregulates quantal AMPA and NMDA currents at neocortical synapses. Neuron 2000; 26: 659-70, https://doi.org/10.1016/S0896-6273(00) 81202-7.

42. Williams J, North R, Shefner S, Nishi S, Egan T. Membrane properties of rat locus coeruleus neurones. Neuroscience 1984; 13: 137-56, https://doi.org/10.1016/0306-4522(84)90265-3.

43. Wuarin J-P, Dudek FE. Patch-clamp analysis of spontaneous synaptic currents in supraoptic neuroendocrine cells of the rat hypothalamus. J Neurosci 1993; 13: 2323-31, https://doi.org/10.1523/JNEUROSCI.13-0602323.1993.

44. Ye G-1, Yi S, Gamkrelidze G, Pasternak JF, Trommer BL. AMPA and NMDA receptor-mediated currents in developing dentate gyrus granule cells. Brain Res Dev Brain Res 2005; 155: 26-32, https://doi.org/10.1016/j. devbrainres.2004.12.002.

45. Zhang L, Bose P, Warren RA. Dopamine preferentially inhibits NMDA receptor-mediated EPSCs by acting on presynaptic D1 receptors in nucleus accumbens during postnatal development. PLoS One 2014; 9: e86970, https://doi.org/10.1371/journal.pone.0086970. 
46. Rezaei Z, Kourosh-Arami M, Azizi H, Semnanian S. Orexin type-1 receptor inhibition in the rat lateral paragigantocellularis nucleus attenuates development of morphine dependence. Neurosci Lett 2020, https:// doi.org/10.1016/j.neulet.2020.134875.

47. Arami MK, Zade JM, Komaki A, Amiri M, Mehrpooya S, Jahanshahi A, et al. Nitric oxide in the nucleus raphe magnus modulates cutaneous blood flow in rats during hypothermia. Iran J Basic Med Sci 2015; 18: 989-92. 